\title{
Satellite Telemetry and Image Reception with Software Defined Radio Applied to Space Outreach Projects in Brazil
}

\author{
DAVID JULIAN M. PERALTA ${ }^{1}$, DOUGLAS S. DOS SANTOS ${ }^{2}$, AURO TIKAMI ${ }^{3}$, \\ WALTER A. DOS SANTOS ${ }^{3}$ and EDSON W.R. PEREIRA ${ }^{4}$ \\ ${ }^{1}$ Programa de Pós-Graduação em Engenharia e Tecnologia Espaciais, Instituto Nacional de Pesquisas \\ Espaciais, Av. dos Astronautas, 1758, 12227-010 São José dos Campos, SP, Brazil \\ ${ }^{2}$ Departamento de Engenharia Eletrônica, Instituto Tecnológico de Aeronáutica, Praça Marechal \\ Eduardo Gomes, 50, Vila das Acácias, 12228-900 São José dos Campos, SP, Brazil \\ ${ }^{3}$ Coordenação de Engenharia e Tecnologia Espacial, Instituto Nacional de Pesquisas Espaciais, \\ Av. dos Astronautas, 1758, 12227-010 São José dos Campos, SP, Brazil \\ ${ }^{4}$ Liga de Amadores Brasileiros de Radio Emissão/LABRE - AMSAT-BR, Rua Dr. Miguel \\ Vieira Ferreira, 345A, Tatuapé, 03071-080 São Paulo, SP, Brazil \\ Manuscript received on November 28, 2017; accepted for publication on February 19, 2018
}

\begin{abstract}
Software Defined Radio (SDR) uses a processor, a special receiver and software that play the main parts of the receiver (mixer, filters, amplifiers, modulators, demodulators, etc.) and it is quite advantageous for its flexibility and compact size as it reduces the amount of hardware components while adapting for different needs. This work briefly presents the SDR concept and approach for obtaining satellite telemetries and imagery in the context of different modulation schemes, link budget requirements and different satellites types. Two case studies are presented for supporting affordable ground segment and promoting satellites projects in Brazil. Reception from the $1^{\text {st }}$ Brazilian picosatellite, Tancredo-1, with specific software developed, UbaTM is presented for obtaining satellite raw telemetries, convert them to engineering value and friendly present on user screen. A series of support software packages are then introduced so that one can pipeline various operations and automate tasks in the ground station. Finally, a second study case was performed in order to receive NOAA class satellites imagery over VHF band and decoded by specific software freely available. Using the proposed SDR approach, it can adapt to projects mainly those with a limited budget and outreach for major inclusion on space topics in Brazil.
\end{abstract}

Key words: ground stations, satellites, Software Defined Radio, space systems.

\section{INTRODUCTION}

Software Defined Radios (SDRs) have been incorporated into ham radio equipment on the market to provide better performance, noise

Correspondence to: Walter Abrahão dos Santos

E-mail: walter.abrahao@inpe.br reduction and digital filtering. SDRs use Digital Signal Processing (DSP) processors for very highspeed digital operations performing typical analog radio functions. The software flexibility provided by SDRs comes from its ability to change its operation allowing the update of new and better 
features and better performance rate without any need to change constantly the hardware (Wyglinski et al. 2016).

Since SDRs are also a cost effective means to obtain satellite telemetry and image reception, they are being extensively employed in the development of pico and nanosatellites projects, also often just called "small satellites", or "smallsats" for short. The use of SDR in the university environment has grown in Latin America significantly in the last 15 years. Besides that, Brazil had a significant increase in the development of such satellites like the cubesats NanoSatC-BR1 (INPE 2014), the AESP-14 (ITA 2015), Serpens (AEB 2015) and the tubesat Tancredo-1 (LABRE 2017), already launched. Other projects like NanoSatC-BR2 and ITASAT are still under development (Ereno and Ramos 2014).

Smallsats platforms are usually project developments with educational and professional goals to design, create, assemble and operate them. They are also developed as an outreach means to train personnel in the future and improve space initiatives on Latin America. The cost of these projects is normally limited, so this is where SDR technology becomes a cost-benefit for the communication link. A rough estimate on how SDR technology costs compared with their fixed item counterparts is around $10 \%$. Therefore, the main motivation of this work is to introduce and demonstrate how SDR-based technology on satellite ground stations for reductions on the development and implementation costs while replacing their major hardware components. This paper's scientific methodology is summarized in Figure 1, where it is shown the typical workflow for receiving and decoding satellites telemetry and NOAA satellite images.

This work is organized as follows: Section 2 discusses the materials and methods used in SDR technology and how it works. Section 3 presents the techniques used and their main results obtained with SDRs in the context of two case studies: a picosatellite and the National Oceanic and Atmospheric Administration (NOAA) satellite. Section 4 discusses the resulting configurations and concludes this paper with general comments and possible future directions.

\section{MATERIALS AND METHODS}

In this section, an overview on the SDR device used is presented, in addition to software and hardware options for obtaining small satellites telemetry decoding and NOAA satellite images.

\section{SDR OVERVIEW}

A SDR employs an RF front-end followed by an analog-to-digital converter in a hardware card as shown in Figure S1 (Supplementary Material) (Superkuh 2017) which samples signals and sends them to a host computer. The rest of the processing is done exclusively in software using the relevant algorithms implemented on the host computer. This allows for greater operational capacity and reduces the cost of other equipment. As an example it can refer to the FUNcube Dongle (Funcube 2017) and the GAUSS Ground Dongle (Gauss 2017).

The use of SDR started in military applications and later, its used in amateur radio was primarily due to the low cost and the availability of its technology. SDRs were also incorporated into the market to provide good performance, noise reduction and digital filtering, even though customized filters still present better performance. Using SDR technology functions such as modulation, demodulation, filtering, encoding, decoding, etc, are done by a software component. They are typically implemented on a general purpose processor, like a DSP (Digital Signal Processing), FPGA (Field Programmable Gate Array), microcontroller, for example (Wyglinski 2016).

The space mission exploration of smallsats requires ground stations that provide the necessary 


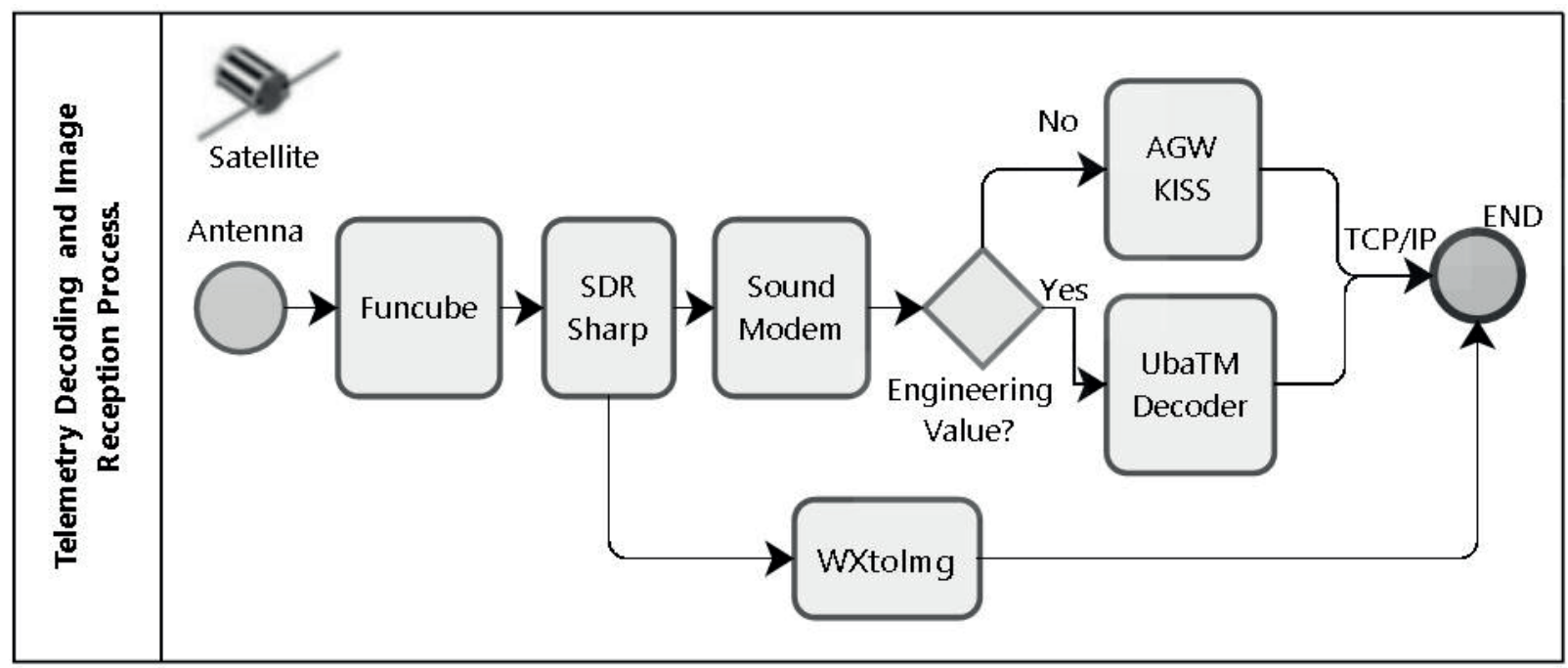

Figure 1 - System diagram of the applied methodology.

support to their operation. Therefore an engineering solution with good cost-benefit is desirable and here is the opportunity to use SDRs (Juang et al. 2008). Often smallsats work in L Band (VHF and UHF) and $\mathrm{S}$ Band and the amateur radio community has been proactive in SDR solutions.

\section{APPLICATION METHOD}

This paper presents the configurations made between several existing software components, which allow, in this case, serving multi-purpose such as a small satellite telemetry decoder and a satellite image decoder. These settings are explained in the results section and are briefly explained below.

Using a SDR adapter as reception hardware and some software elements for signal processing, we explain the different configurations that shall be made to obtain a telemetry decoder, for example.

Similarly, using the same signal receiver hardware, we explain the process for receiving information from the United States NOAA series of weather satellites (NOAA 2017). More specifically, the NOAA-15, NOAA-18 and NOAA-19 satellites were targeted and the software tools that allow signal processing and decoding were used for each satellite image sent.

\section{HARDWARE AND SOFTWARE APPLICATION OPTIONS}

The implementation of a cost-effective solution for SDR-based tracking of small satellites involves a series of hardware and software elements, which are interconnected with each other and, provide the function of reception and decoding of the signals sent by the satellite.

Some of the points presented hereafter are software options available mainly for the downlink monitoring that are suitable for a casual satellite tracking but are not quite adequate to be integrated into a ground station system that needs sometimes to function autonomously.

\section{Hardware options for tracking satellites}

The hardware part of this infrastructure may be as simple: (1) Laptop, (2) Funcube Dongle Pro Plus (Funcube 2017) shown in Figure S2, or similar SDRs and, (3) RF Antenna.

For the RF part, many solutions can be used and one chosen for this work is a MoxonZBZ antenna (Moxon 2003) shown in Figure 2 with two elements in VHF and four elements in UHF. 


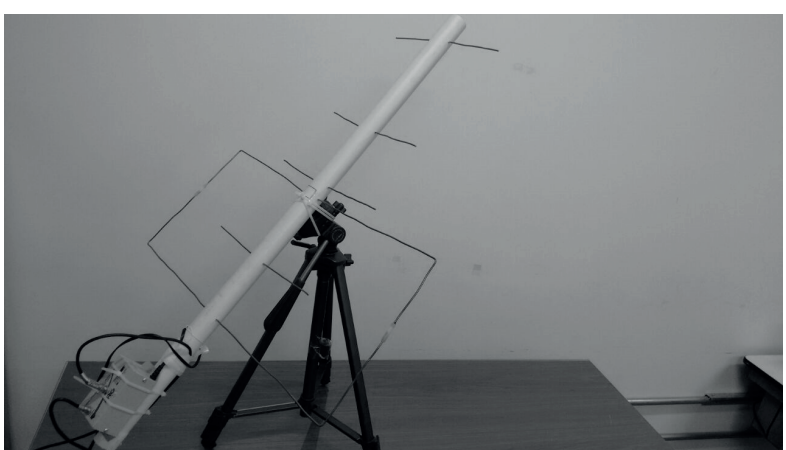

Figure 2 - Antenna VHF and UHF hand-assembled for receiving the satellite signals.

\section{Software options for tracking satellites}

There is a great amount of software packages available for various platforms from desktop to mobiles. This work calls attention to some which are available free of charge making them suitable for projects that run on a budget, namely: HeavensAbove, Orbitron, SDRSharp, SoundModem (Peralta 2017) besides many others such as GNU Radio (GNURADIO 2017).

For example, the Heavens-Above app on Android (Peat 2015), shown in Figure S3, has a list of satellites, including those dedicated to radio amateur, with information about them and about their passes.

Orbitron (Stoff 2005) is a well-known software to track satellites, shown in Figure 3, providing real time and simulated position and pointing antennas according to their azimuth and elevation.

SDR Sharp by AIRSPY (Airspy 2016) is an application that replaces conventional physical radios, shown in Figure S4, it allows one to listen to the signals sent by the satellite.

SoundModem v.95 by UZ7HO (Uz7ho 2016) is a software modem that demodulates digital signals into binary data, shown in Figure S5. It processes the audio signals from a conventional (analog) or SDR receiver as well as generates digital modulation to be transmitted.

Finally, AGW Online Kiss v. 2.4.4 by DK3WN (Peøsat 2015). This software decodes AX.25 KISS frames from SoundModem into raw values as shows in Figure S6. The telemetry values sent by any satellite are obtained and visualized in raw data.

\section{Software configuration}

The software configuration is implemented with the previously mentioned software tools. In Figure S7, the software interrelationship diagram is shown. For this diagram, it should be noted that there are two possible final elements. Each telemetry hexadecimal value can be obtained as well as its engineering value, but in this case, only if one has specific software for the satellite, which performs all the necessary calculations and converts the data to values that can be easily understood by the user.

Regardless of the result to be obtained, the following process must be performed:

- Initially the receiver hardware (SDR) must be properly connected to the antenna that operates in the frequency band (VHF - Very High Frequency).

- Connect the receiver hardware to the equipment where the decoding will be performed.

- Execute the program SDRSharp, which serves as receiver of the signal sent by satellite, it should be to configure all the necessary parameters for each satellite (frequency of operation, modulation, bandwidth, etc.).

- Run the program SoundModem, which receives the sound sent by SDRSharp and demodulates signals, in our case AX-25 frames, the information and display it in ASCII language.

- At this point, one can choose one of the following options, depending on the tools with which one count.

- Execute the program AGW Online KISS, which will receive the SoundModem program Information, to realize the 


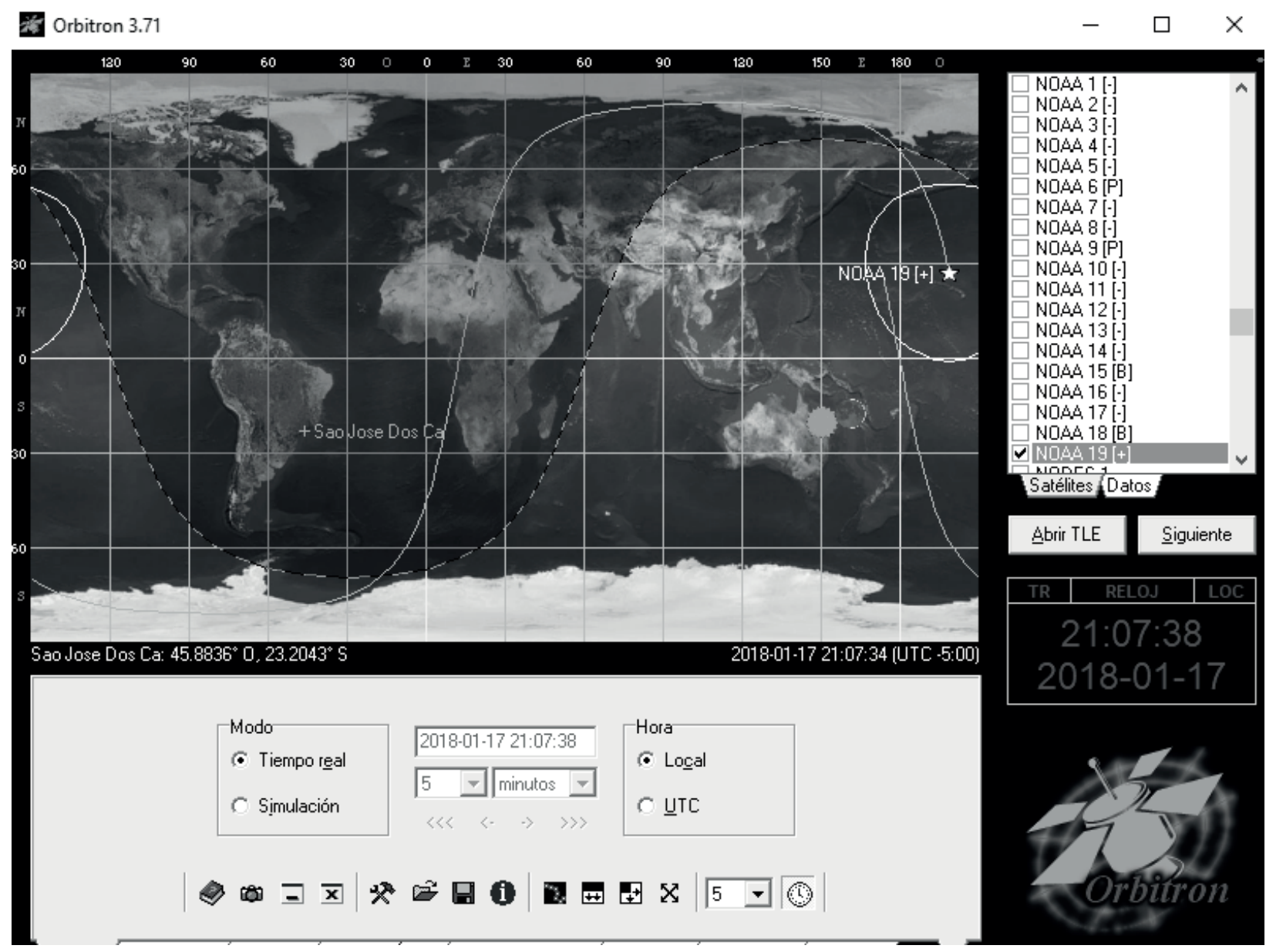

Figure 3 - Orbitron screenshot with satellite tracking information.

codification and to show each telemetry in hexadecimal value.

- Run the telemetry satellite decoder software to obtain the engineering value of each telemetry. In our case, run the UbaTM software to convert the telemetry raw values into suitable engineering values.

It is necessary to configure the communication between decoding software (SoundModem, AGW Online KISS, own TM satellite software) by TCP/ IP communication.

\section{Interoperability issues in the tracking software} and a case study

Interoperability issues (Konstantat et al. 2006) appear when one tries to track a satellite and has to put together all aforementioned software packages in order to get telemetry data for example. From this scenario, there are two possible types: one part is from the received sound input to the output and the other is between application network ports. More precisely these are detailed hereafter:

- The sound output of the SDRSharp, becomes the signal input of the SoundModem program (by physical cables, virtual cables or simply the sound card of the machine) for demodulating AX-25 signals into binary encoded information.

- Binary encoded information provided by SoundModem is sent via a communication port, either on a local or a remote machine (IP address). 


\section{RESULTS}

The results were obtained executing two different case studies namely: (1) Telemetry decoding of a Brazilian picosatellite and (2) Image decoding of a NOAA satellite.

CASE STUDY 1 - TANCREDO-1 PICOSATELLITE TELEMETRY DECODING

This case study aims at receiving the telemetry signals and obtaining the engineering value of the telemetry data sent by the Brazilian picosatellite Tancredo-1, launched in January, 2017.

Initially, the link budget needs to be checked for certifying that satellite reception is feasible. This starts with Tancredo- 1 picosatellite main RF characteristics listed below:

- Transmission power $\boldsymbol{P}_{t}=\mathbf{- 3} \mathrm{dBW}$.

- Total transmission line losses $\boldsymbol{L}_{\boldsymbol{t l}}=2 \mathrm{~dB}$.

- Antenna gain $\boldsymbol{G}_{a}=2.2 \mathrm{~dB}$.

Therefore, the Effective Isotropic Radiated Power (EIRP) is given by:

$\boldsymbol{E I R P}=\boldsymbol{P}_{t} \cdot \boldsymbol{L}_{t l}, \boldsymbol{G}_{a}=-2.8 \mathrm{dBW}$

The signal level received at the Earth in the vicinity of the ground station using an omnidirectional antenna is given by spacecraft EIRP subtracted by downlink path losses. The major loss is due to Free Space Loss (FSL) which is given by:

$F S L=10 \log [4 \pi \cdot d \cdot f / c]^{2}=150.1 \mathrm{~dB}$

Where $\boldsymbol{d}=1732 \mathrm{~km}$ for a slant range, the frequency $\boldsymbol{f}=437.5 \mathrm{MHz}$ and $\boldsymbol{c}=3 \times 10^{8} \mathrm{~m} / \mathrm{s}$.

Other losses have also to be determined due to mainly by atmospheric, ionospheric, antenna pointing and antenna polarization. Estimating these losses equal $3.0 \mathrm{~dB}$, the isotropic signal level at ground station, as depicted in Figure S8, $\boldsymbol{E I R P}_{G S}$ is $-155.9 \mathrm{dBW}$ for a generic ground station block diagram.
The ground station link margin can be then calculated from $\boldsymbol{E}_{b} / \boldsymbol{N}_{o}$ method or from SNR method. This method is presented here where the first step is to calculate Ground Station Effective Noise Temperature, $\boldsymbol{T}_{S}$ is given by the expression:

$T_{S}=(\alpha) T_{a}+(1-\alpha) T_{o}+T_{L N A}+T_{2 n d S t a g e} /\left(G_{L N A} / L_{D}\right)$

Where:

$\boldsymbol{T}_{\boldsymbol{a}}=$ Antenna Temperature or Sky Temperature $\left({ }^{\circ} \mathrm{K}\right)=500 \mathrm{~K}$

$\boldsymbol{T}_{\boldsymbol{o}}=$ System Line Temperature (Physical Temperature) $\left({ }^{\circ} \mathrm{K}\right)=290 \mathrm{~K}$

$\boldsymbol{T}_{L N A}=$ Noise Temperature of the Low Noise Amplifier $\left({ }^{\circ} \mathrm{K}\right)=60 \mathrm{~K}$

$\boldsymbol{T}_{\text {2nd Stage }}=$ Noise Temperature of Next Stage Amplifier or Mixer $\left({ }^{\circ} \mathrm{K}\right)$

$\boldsymbol{G}_{L N A}=$ Gain of the LNA in linear (non-dB) units $=63.1(18 \mathrm{~dB})$

$\boldsymbol{L}_{\boldsymbol{D}}=$ Insertion Loss of any other In-Line device in front of LNA $(\mathrm{dB})=2.3 \mathrm{~dB}$

$\boldsymbol{\alpha}=$ Feed Line Coefficient given by:

$\alpha=10^{-(L a+L b+L c+L} \quad+{ }_{\text {other }}^{+L} / 10$

Where:

$\boldsymbol{L}_{\boldsymbol{a}}, \boldsymbol{L}_{\boldsymbol{b}}, \boldsymbol{L}_{\boldsymbol{c}}=$ All cable or waveguide Losses (dB)

$\boldsymbol{L}_{b p f}=$ Insertion Loss of any bandpass filter used in front of LNA (dB)

$\boldsymbol{L}_{\text {other }}=$ Losses due to other in-line device (dB)

Estimating the total in-line losses from the antenna to LNA equal $0.48 \mathrm{~dB}$, we then from (4) we have the Transmission Line Coefficient $\boldsymbol{\alpha}=0.8954$. Thence, from (3) we derive the Ground Station Effective Noise Temperature to be $\boldsymbol{T}_{S}=565 \mathrm{~K}$.

The next step is to determine the Ground Station Figure of Merit $(\boldsymbol{G} / \boldsymbol{T})$ given by:

$G / T=G_{a}-L_{t l G S}-10 . \log \left(T_{s}\right)$

Where we estimate:

$\boldsymbol{G}_{a}=$ Ground Station Antenna Gain $=24 \mathrm{dBi}$

$L_{t / G S}=$ Ground Station Total Transmission Line Losses $=0.5 \mathrm{~dB}$ 
Therefore, we have $\boldsymbol{G} / \boldsymbol{T}=-4.02 \mathrm{~dB} / \mathrm{K}$. Next, we calculate the Signal-to-Noise Power Density ( $\boldsymbol{S} /$ $\boldsymbol{N}_{o}$ ) and $\boldsymbol{E}_{b} / \boldsymbol{N}_{o}$ given by:

$S / N_{o}=E I R P_{G S}-L_{G S A P}+(G / T)-K$

Where $\boldsymbol{K}=$ Boltzman's constant $=-228.6$ $\mathrm{dBW} / \mathrm{K} / \mathrm{Hz}$ and $\boldsymbol{L}_{G S A P}=$ Ground Station Antenna Pointing Loss $=0.4 \mathrm{~dB}$ (estimated). Thence, $\boldsymbol{S} / \boldsymbol{N}_{\boldsymbol{o}}=$ $68.28 \mathrm{dBHz}$ and using:

$E_{b} / N_{o}=S / N o-10 \log (R)$

Where $\boldsymbol{R}=$ data rate, then $\boldsymbol{E}_{\boldsymbol{b}} / \mathbf{N}_{\boldsymbol{o}}=37.48 \mathrm{~dB}$ for $\boldsymbol{R}=1200$ bps.

According to IARU, Modulation Demodulation Method spreadsheet the required $\boldsymbol{E}_{\boldsymbol{b}} / \boldsymbol{N}_{\boldsymbol{o}}$ is $21 \mathrm{~dB}$ for AFSK/FM modulation and $\boldsymbol{B} \boldsymbol{E} \boldsymbol{R}$ equals $10^{-4}$ and considering demodulator implementation loss equals $1 \mathrm{~dB}$, we have a $\boldsymbol{E}_{b} / \boldsymbol{N}_{\text {othreshold }}=22 \mathrm{~dB}$. Therefore, the system link margin will be:

$\boldsymbol{E}_{\boldsymbol{b}} / \boldsymbol{N}_{\boldsymbol{o}}-\boldsymbol{E}_{\boldsymbol{b}} / \boldsymbol{N}_{\text {othreshold }}=37.48-22=15.48 \mathrm{~dB}$

This ascertains that signal reception is feasible.

On the processing side, after sorting out all operability issues mentioned earlier, an output port from the SoundModem has to be connected to a telemetry decoder. For this purpose, a software called UbaTM, its main window is shown in Figure 4, was developed for converting the telemetry raw values into engineering units and presents the telemetry information in an easy-to read manner. UbaTM was developed by Edson Pereira, PY2SDR, as a contribution for UbatubaSat project.

\section{CASE STUDY 2 - NOAA SATELLITES IMAGE DECODING}

For this part of the experiment the SDRSharp program is used. The same connection scheme of all hardware elements is used, the receiving hardware must be connected to the equipment where the image will be decoded and processed, clearly the VHF receiver antenna, must also be properly connected to the SDR receiver hardware. The Figure S9 shows the scheme of operation between the hardware and software elements for reception and decoding of NOAA satellites images.

In the same way that the SDRSharp program is used for the telemetry decoder explained above, it should be used to obtain images of the NOAA weather satellites, with the difference that for each of the NOAA satellites, the communication parameters between satellite and the ground must be established, in order to be able to process and decode that signal to finally acquire a satellite meteorological image.

Additionally, to acquire the images of these satellites, a special tool is necessary, a software called WXtoImg (WXtoImg 2015), which allows the decoding and visualization in real time of the satellite images.

WXtoImg is a fully automated APT and WEFAX weather satellite (wxsat) decoder. The software supports recording, decoding, editing, and viewing on all versions of Windows, Linux, and Mac OS X. WXtoImg supports real-time decoding, map overlays, advanced colour enhancements, 3-D images, animations, multi-pass images, projection transformation (e.g., Mercator), text overlays, automated web page creation, temperature display, GPS interfacing, wide-area composite image creation and computer control for many weather satellite receivers, communications receivers, and scanners.

The process begins with the configuration of SDRSharp, establishing the appropriate configuration for the reception of each satellite's signal. It should indicate the signal source to be used, i.e. the type of receiver being used, for example: Airspy, Funcube Dongle Pro, Funcube Dongle Pro Plus, RTL-SDR, etc, this is to ensure that the input signal is being captured by the correct hardware.

In the Audio panel, it must establish the input and output mechanisms to work, in this case the 


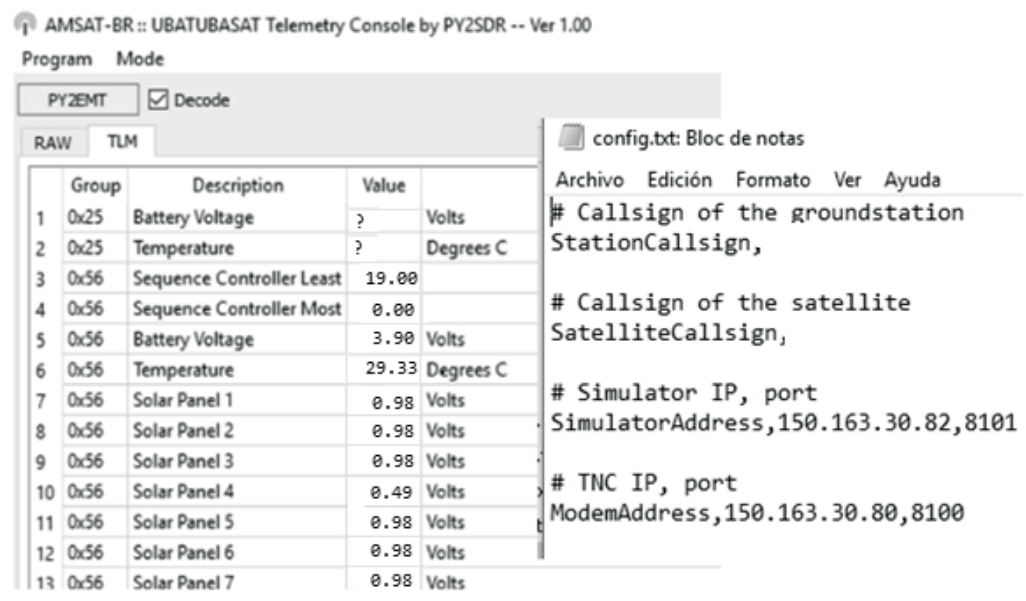

Figure 4 - UbaTM Decoder with engineering valued telemetry and configuration file.

audio input will be the same receiver hardware used (SDR). In the output, it must be ensured that the equipment's audio output is returned to it, i.e. the audio generated by SDRSharp must be converted into an input source for the WXtoImg decoding software. In this case, the type of output must be chosen as available. In this case, either a physical cable that connects from the Audio Output Port to the equipment's Audio Input Port, or a software that works as a "virtual cable". The computer's sound card can also be used, but this does not guarantee a good flow of audio information.

It is important to know the satellite operation frequency in order to follow it and receive its images. Using the SharpSDR, the frequency selection can be done either manually or automatically via plugins. Below the satellites that are in operation and their download frequency are listed.

- NOAA-15: 137,62 MHz.

- NOAA-18: 137,9125 MHz.

- NOAA-19: 137,1 MHz.

Afterwards, the WXtoImg program must be configured, assigning the geographical point from which the satellite is being tracked. Furthermore, the Orbitron software can be used to visually track the satellite current position, in order to start acquiring the image at the right time. Orbitron TLE database updates are done while system is on-line.
When the satellite enters the viewing range of the ground station, the antenna pointing and the reception of the satellite signal are started. When the system is receiving a constant signal, the "Autorecord" facility shall be used for receiving the image in real time. In the Figure 5, a screenshot, shows the reception process of an image of the satellite NOAA-19, whereby the two software are working simultaneously (SDRSharp and WXtoImg)

In the Figure S10 shows the final image captured on July 3, 2017, in the São Jose dos Campos city, São Paulo State, Brazil, obtained from the NOAA-19 satellite.

The WXtolmg tool allows making enhancements to each of the acquired images, to obtain the better image visualization quality. This experiment was performed using the Funcube Dongle Pro Plus receiver SDR, for more information about image acquisition processes using RTL-SDR, one can consult the tutorial available in (RTL-SDR 2013).

\section{DISCUSSION AND CONCLUSION}

From the results obtained, there are powerful tools for use in the aerospace sector, especially to acquire data from the satellite. These tools and their 


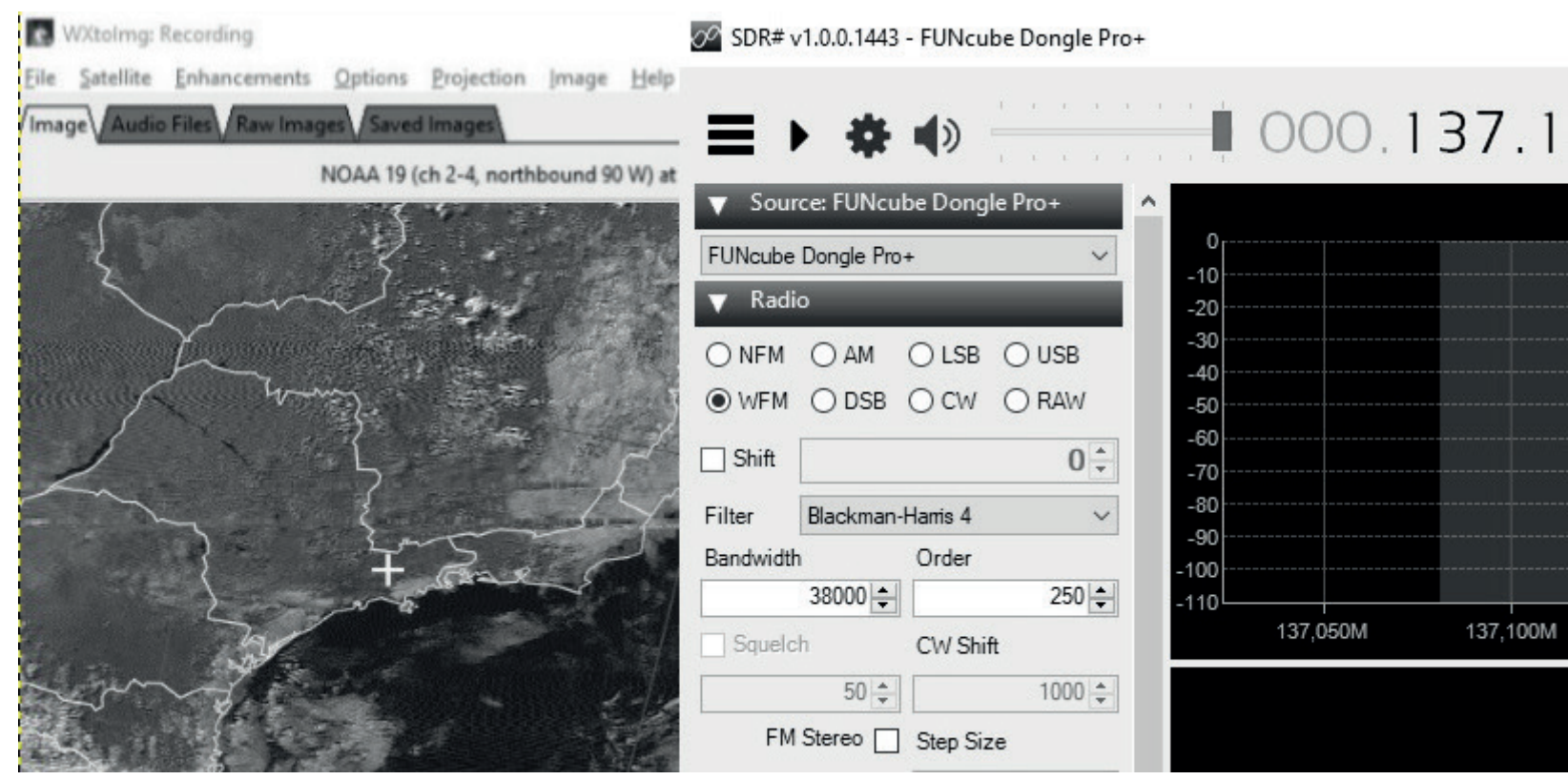

Figure 5 - SDRSharp and WXtoImg working for image reception.

configurations, as presented in this paper, enables a work environment for easy understanding and use. Although, they may not work exactly for all low orbiting satellites or small satellites, they still constitute a means for adaptation or development of new tools that may be more portable and with better operational capabilities.

This study's motivation was to reduce the cost for monitoring mainly the downlink of smallsats projects, which mostly run on a constraint budget. Therefore, it presents the use of software tools and few hardware elements that facilitate the assembly of a simple ground station able to receive and decode the signal sent by a satellite. The material presented is one solution that was used for monitoring telemetry signal from a picosatellite named Tancredo- 1 as a case study and a proof of concept.

Project participants have become aware of the information flow starting from the RF signal acquisition up to the decoded engineering-value telemetry. Still they are able to reduce tracking costs in large percentage compared to solution based on fixed stations currently available on the market depending on their cost-benefit analysis. In order to provide reliability, there is a need for further development of better software solutions.

The software packages mentioned in this work, in conjunction with the hardware elements, allow telemetry decoding. Part of this chained processing is satellite independent and only the final stream, when the engineering values of telemetries are derived, are satellite sensitive. In this case, it is necessary to know the configuration and the structure of each of telemetry data.

Since the solution employed does not work "as is" for most satellites in orbit, further development is needed so future work will concentrate on more flexible SDR frameworks such as GNUradio.

\section{ACKNOWLEDGMENTS}

The authors acknowledge Coordenação de Aperfeiçoamento de Pessoal de Nível Superior (CAPES-Brazil) for supporting this research.

\section{REFERENCES}

AEB - AGÊNCIA ESPACIAL BRASILEIRA. 2015.

Nanosatélite Serpens está em órbita e tem sinais captados 
no Brasil. Disponível em: http://www.aeb.gov.br/ nanossatelite-serpens-esta-em-orbita-e-tem-sinaiscaptados-no-brasil/. Acesso em 16 de maio de 2017.

AIRSPY. 2016. Airspy Low Cost High Performance SDR SDR Sharp. Available at: http://airspy.com/download/. Acessed on July 5, 2017.

ERENO D AND RAMOS L. 2014. Pequenos ganham o espaço. Disponível em: http://revistapesquisa.fapesp. br/2014/05/15/pequenos-ganham-o-espaco/. Acesso em 17 de maio de 2017.

FUNCUBE. 2017. The FUNcube Dongle Pro+: LF to L band software-defined radio. Available at: http://www. funcubedongle.com/. Acessed on May 17, 2017.

GAUSS - GROUD OF ASTRODYNAMICS FOR THE USE OF THE SPACE SYSTEM. 2017. Available at: https:// www.gaussteam.com/services/satellite-subsystem/radio/. Acessed on May 17, 2017.

GNURADIO. 2017. About GNU Radio. Available at: https:// www.gnuradio.org/about/. Acessed on Aug 16, 2017.

INPE - INSTITUTO NACIONAL DE PESQUISAS ESPACIAIS. 2014. NanosatC-BR1 é lançado com sucesso e estação já recebe sinais do primeiro cubesat nacional. Disponível em: http://www.inpe.br/noticias/noticia. php?Cod_Noticia=3640. Acesso em 16 de maio de 2017.

ITA - INSTITUTO TECNOLÓGICO DE AERONÁUTICA. 2015. Cubesat brasileiro lançado com sucesso da estação espacial internacional. Disponível em: http:/www.ita.br/ noticias14. Acesso em 16 de maio de 2017.

JUANG JC, TSAI CT AND MIAU JJ. 2008. A SoftwareDefined Radio Approach for the Implementation of Ground Station Receivers. Small Satellites for Earth Observation. Netherlands: Springer Verlag, p. 293-298.

KONSTANTAS D, BOURRIĖRES JP, LÉONARD M AND BOUDJLIDA N. 2006. Interoperability of Enterprise Software and Applications. Proceedings of the I-ESA Conferences, Springer-Verlag London, 466 p.

LABRE - LIGA DE AMADORES BRASILEIROS DE RADIO EMISSÃO. 2017. AMSAT-BR Tubesat Tancredo-1 é ejetado e inicia transmissões. Available at: http://amsat-br. org/. Acesso em 17 de junho de 2017.

MOXON P. 2003. Moxon Antenna Project. Available at: http:// www.moxonantennaproject.com/index.html. Acessed on July 5, 2017.

NOAA - NATIONAL OCEANIC AND ATMOSPHERIC ADMINISTRATION'S. 2017. U.S. Department of Comerce. Available at: http://www.noaa.gov/satellites. Acessed on August 10, 2017.

PEAT C. 2015. Heavens Above Application. Available at: http://www.heavens-above.com/. Acessed on July 5, 2017.
PEØSAT AR. 2015. Information about Amateur Radio Satellite experiments. Available at: http://www.pe0sat. vgnet.nl/decoding/tlm-decoding-software/dk3wn/. Acessed on July 5, 2017.

PERALTA DJM, TIKAMI A, SANTOS DS, DOS SANTOS WA AND PEREIRA EWR. A Software Defined Radio Approach to Ground Operations of Small Satellites. Proc. of the $1^{\text {st }}$ IAA Latin American Symposium on Small Satellites. Buenos Aires, March, 2017.

RTL-SDR. 2013. RTL-SDR Tutorial: Receiveing NOAA Weather Satellite Images. Available at: http://www.rtlsdr.com/rtl-sdr-tutorial-receiving-noaa-weather-satelliteimages/. Acessed on July 8, 2017.

STOFF S. 2005. Orbitron - Satellite Tracking System. Available at: http://www.stoff.pl/. Acessed on July 5, 2017.

SUPERKUH. 2017. RTL-SDR and GNU Radio with Realtek RTL2832U software defined radio receivers. Available at: http://superkuh.com/rtlsdr.html. Acessed on May 17, 2017.

UZ7HO. 2016. Personal Page of Uz7ho - The software PacketRadio TNC. Available at: http://uz7.ho.ua/packetradio. htm. Acessed on July 5, 2017.

WXTOIMG. 2015. Software to decode APT and WEFAX signals from weather satellites. Available at: http://www. wxtoimg.com/. Acessed on July 6, 2017.

WYGLINSKI AM, OROFINO DP, ETTUS MN AND RONDEAU TW. 2016. Revolutionizing software defined radio: case studies in hardware, software, and education. IEEE Communications Magazine 54(1): 68-75.

\section{SUPPLEMENTARY MATERIAL}

FIGURE S1 - SDR hardware adapter (Superkuh 2017).

FIGURE S2 - Funcube Dongle Pro Plus connected to computer.

FIGURE S3 - Heavens-Above app screens on passing-by satellites.

FIGURE S4 - SDR sharp screen with spectrum of received signal.

FIGURE S5 - Soundmodem application converting raw data into binary.

FIGURE S6 - AGW Online Kiss program with raw and configuration file.

FIGURE S7 - Schematic diagram for the telemetry decoding progress.

FIGURE S8 - A typical ground station block diagram.

FIGURE S9 - Schematic diagram for image reception of images from NOAA satellites.

FIGURE S10 - Final image obtained from NOAA-19 satellite. 